Article

\title{
Governing and Delivering a Biome-Wide Restoration Initiative: The Case of Atlantic Forest Restoration Pact in Brazil
}

Severino R. Pinto ${ }^{1,2, *}$, Felipe Melo ${ }^{2}$, Marcelo Tabarelli ${ }^{2}$, Aurélio Padovesi ${ }^{3}$, Carlos A. Mesquita ${ }^{4}$, Carlos Alberto de Mattos Scaramuzza ${ }^{5}$, Pedro Castro ${ }^{6}$, Helena Carrascosa ${ }^{7}$, Miguel Calmon ${ }^{8}$, Ricardo Rodrigues ${ }^{9}$, Ricardo Gomes César ${ }^{10}$ and Pedro H. S. Brancalion 10

1 Centro de Pesquisas Ambientais do Nordeste (Cepan), Rua Dom Pedro Henrique, 167, Recife, PE, Brazil

2 Departamento de Botânica, Universidade Federal de Pernambuco, Av. Prof. Moraes Rego s/n, Recife, PE, Brazil; E-Mails: felipe.plmelo@ufpe.br (F.M.); mtrelli@ufpe.br (M.T.)

3 The Nature Conservancy, Avenida Paulista, São Paulo, SP, Brazil; E-Mail: apadovezi@tnc.org

4 Diretor para a Mata Atlântica da Conservação Internacional, doutorando do Laboratório de Gestão Ambiental, Programa de Pós-Graduação em Ciências Ambientais e Florestais, Universidade Federal Rural do Rio de Janeiro (UFRRJ), Brazil; E-Mail: c.mesquita@conservation.org

5 Secretaria de Biodiversidade e Florestas, Ministério do Meio Ambiente (MMA), Distrito Federal, Brasília, DF, Brazil; E-Mail: carlos.scaramuzza@mma.gov.br

6 Secretaria Executiva do Pacto pela Restauração da Mata Atlântica, Rua do Horto, 931, Casa das Reservas da Biosfera, São Paulo, SP, Brazil; E-Mail: secretariaexecutiva@pacto.org.br

7 Secretaria do Meio Ambiente, São Paulo, SP, Brazil; E-Mail: hcarrascosa@sp.gov.br

8 Global Forest and Climate Change Programa (GFCCP), International Union for Conservation of Nature, Washington, DC, USA; E-Mail: miguel.calmon@iucn.org

9 Laboratory of Forest Ecology and Restoration (LERF), Department of Biological Sciences, ESALQ, University of São Paulo, Av. Pádua Dias,11, P.O. Box 9, 13418-900 Piracicaba, São Paulo, Brazil; E-Mail: rrresalq@usp.br

10 Laboratory of Tropical Forestry (LASTROP), Department of Forest Sciences, ESALQ — University of São Paulo, Av. Pádua Dias, 11, P.O. Box 9, 13418-900 Piracicaba, São Paulo, Brazil; E-Mails: ricardogoce@yahoo.com.br (R.G.C.); pedrob@usp.br (P.H.S.B.)

* Author to whom correspondence should be addressed; E-Mail: severino@cepan.org.br; Tel.: +55-81-3423-5851; Fax: +55-81-3423-5851.

Received: 11 February 2014; in revised form: 2 September 2014 / Accepted: 4 September 2014 / Published: 19 September 2014 


\begin{abstract}
In many human-modified tropical landscapes, biodiversity conservation and the provision of ecosystem services require large-scale restoration initiatives. Such initiatives must be able to augment the amount and the quality of remaining natural habitats. There is thus a growing need for long-term, multi-stakeholder and multi-purpose initiatives that result in multiple ecological and socioeconomic benefits at the biome scale. The Atlantic Forest Restoration Pact (AFRP) is a coalition of $260+$ stakeholders, including governmental agencies, private sector, NGOs and research institutions, aimed at restoring 15 million ha of degraded and deforested lands by 2050 . By articulating, and then integrating common interests, this initiative has allowed different sectors of society to implement an ambitious vision and create a forum for public and private concerns regarding forest restoration. The AFRP adopts a set of governance tools so multiple actors can implement key processes to achieve long-term and visionary restoration goals. Having overcome some initial challenges, AFRP now has to incorporate underrepresented stakeholders and enhance its efforts to make forest restoration more economically viable, including cases where restoration could be less expensive and profitable. The AFRP experience has resulted in many lessons learned, which can be shared to foster similar initiatives across tropical regions.
\end{abstract}

Keywords: Atlantic Forest; governance; restoration; Atlantic Forest Restoration Pact

\title{
1. Introduction
}

In many human-modified tropical landscapes, the conservation of biodiversity and the provision of ecosystem services require innovative, large-scale restoration initiatives, which should seek to augment the amount/quality of natural habitats via the inclusion of both remaining forest patches and those undergoing restoration [1]. However, governments have only recently started to develop environmental policies aimed at reducing deforestation and promoting reforestation. Many countries are addressing their environmental problems and, more recently, their need to increase native vegetation cover through state-led and complex legal/regulatory instruments, which could (a) be excessively bureaucratic, (b) operate via top-down approaches, and (c) focus on legal compliance and punishment, instead of rewarding positive actions. Such approaches have failed to encourage better practices, resulting in low involvement and a lack of participation among multiple stakeholders, especially in regions with poor governance and weak legal enforcement [2]. In the context of ecological restoration initiatives in developing countries, a bottom-up approach could create good opportunities to overcome some of the legal, technological, and economic challenges frequently experienced by these initiatives $[3,4]$. In this context, the ambitious goal established by the Aichi Target 15 of the United Nations Convention on Biological Diversity to restore 15\% of all degraded ecosystems on Earth by 2020 (about 150 million ha), as well as by the Bonn Challenge, requires well-coordinated and articulated initiatives [5]. As only a few countries, such as South Africa, the United States of America, Ethiopia, China and Costa Rica [6-8], have already started to implement large-scale initiatives, little information is available concerning instruments of governance and the coordination of restoration initiatives. It is imperative, therefore, that 
any lessons learned through both successful and unsuccessful experiences should be shared for the sake of large-scale forest restoration initiatives worldwide [9].

We describe here the socio-ecological context, the instruments of governance and the key challenges/lessons experienced by the Atlantic Forest Restoration Pact (hereafter AFRP), a biome-wide restoration program that represents the largest forest restoration initiative currently being implemented in Latin America [10]. We first address the degradation of the Brazilian Atlantic Forest and offer a historical perspective on the legal instruments and policies related to ecological restoration in this irreplaceable biome. We then contextualize why and how the AFRP was created, and discuss the governance structure specifically designed to achieve the AFRP's major goals and objectives in a dynamic environment of both opportunities and potential constraints. Finally, we highlight the major achievements of this restoration initiative and share the present and future challenges towards the implementation of this large-scale, multi-stakeholder forest restoration program with a view to inspiring and fostering similar initiatives across other tropical regions.

\section{The History of Atlantic Forest Degradation}

Even before the Portuguese settlers arrived in Brazil in 1500, the Atlantic Forest was already subject to some level of anthropogenic disturbance. The biome had become quite densely populated during the apex of the Tupi domination - a heterogeneous indigenous group that dominated the Brazilian Atlantic coast for approximately 1000 years before the arrival of European settlers - reaching around 600 people per $70 \mathrm{~km}^{2}$ [11]. The Tupi people practiced nomadic slash-and-burn agriculture, and may have burned their entire territory - which was in the Atlantic forest biome - every 55 years (i.e., during 1000 years of tupi domination, each forest patch appropriate for agriculture was probably burned dozens of times [11]). However, the site-specific and sporadic nature of this cultivation system did not impact the Atlantic Forest significantly and allowed for its vigorous re-growth after the Tupi societies collapsed.

Once the European settlers did not immediately find gold and silver to provide income to the Portuguese crown, they overexploited Brazilwood trees (Caesalpinia echinata) as a source of red dye for cloth, impacting nearly 600,000 ha of forest in the first century of European occupation [11]. The country's name derives from this endemic tree species of the Atlantic Forest, a species currently threatened by extinction. Concomitantly, the Portuguese crown provided land concessions in order to encourage people to consolidate the occupation of Brazilian territory and expand the sugarcane plantation monoculture. Once soils had been completely depleted, new concessions were provided in forest lands, thus creating an expanding and vast network of degraded sugarcane plantation lands. At the end of the 17th Century the Portuguese finally found significant amounts of gold in Brazil and initiated the third economic cycle of the country: gold mining. Agriculture expanded to feed a growing population, and the resulting economic boom destroyed another 3 million ha of forests in the 18th Century [11]. Later, from the mid-19th Century to the beginning of the 20th Century, coffee plantations ended this historical deforestation process in the Atlantic Forest and occupied a major proportion of the southeastern region of the country. To illustrate the severity of deforestation, in the state of São Paulo the remaining Atlantic Forest cover was reduced from 80 to 8\% between 1854 and 1973, due largely to coffee expansion to sustain exports to the US and Europe [12]. In sum, all of the historical economic 
cycles of Brazil occurred at the expense of the Atlantic Forest, the remainder of which is now recognized as one of the top-five global biodiversity Hotspots [13].

After nearly 500 years of massive land use change in the Atlantic Forest, this biome currently has less than $12 \%$ of its original forest cover $\left(1.2\right.$ million $\left.\mathrm{km}^{2}\right)$ but houses more than $60 \%$ (c.a. 120 million) of the Brazilian population. In addition, the region is responsible for nearly $80 \%$ of all Brazilian GDP [14-16]. As a result of an intense process of public land privatization from 1850 forward, with the enactment of the Lei de Terras (Law \# 601/1850), approximately $90 \%$ of the remaining Atlantic Forest is privately held [17]. Thus, the involvement of private landholders in forest restoration initiatives is crucial for both biodiversity conservation and the provisions of ecosystem services in this biome.

\section{The Socio-Ecological Context of Habitat Restoration in the Atlantic Forest}

Forest restoration initiatives in the Atlantic Forest region started more than 150 years ago. In the late 19th Century, the city of Rio de Janeiro faced water shortages because of the conversion of its original forests/watersheds to agriculture. To reverse this, Emperor Dom Pedro II ordered the planting of thousands of seedlings from 1862 to 1892 , and today this forest stands as the Tijuca Forest National Park. Nevertheless, despite this pioneering initiative, it took another one hundred years before forest restoration became truly relevant again in Brazil. Throughout the 20th Century, Brazil enacted a series of legal instruments supporting sustainable use of the forests. These decrees became consistently stronger, eventually obliging farmers to protect key areas for ecosystem services provisioning and requiring private companies to compensate for some of the environmental damage they cause.

The first of these legal instruments was the Forest Code in 1934 (Decree \# 23793/1934), which stated that all native forests were of public interest, with an obligation for all rural properties to maintain a certain amount of forest habitat to benefit the entire society. It included a visionary concept of "protective forests", which refer to vegetation that should be conserved to maintain ecosystem services, such as soil retention and water provisioning. However, the law did not establish clearly how much and where, any native forest should be conserved in rural areas. This lack of precision in the law's definitions made enforcement difficult. Thus, in 1965, a revised version of the Forest Code was established (Law \#4771/1965), which defined the areas where forests should be preserved-and in some cases restored - to maintain ecosystem services (Areas of Permanent Preservation). It also defined an additional minimum percentage of forest cover for each property (Legal Reserve), which could be used for sustainable timber harvesting [18]. However, weak environmental governance and the consequent poor compliance with the law hampered the effectiveness of the Forest Code as an instrument to reduce deforestation rates and to foster forest restoration in agricultural landscapes. In the context of large private companies, forest restoration was further stimulated from 1981 forward by the National Environmental Policy (Law \# 6938/1981), which established the restoration of degraded lands as part of offsetting policies for companies whose activities cause environmental impacts. This legal instrument boosted forest restoration mainly for mining and hydroelectric companies, which had to compensate for the deforestation caused by their activities.

Following a global trend in reinforcing environmental protection, the Brazilian Federal Constitution established, in 1988, that public authorities should promote restoration of ecological processes in order to guarantee a healthy environment for the Brazilian society. As a consequence, new legal instruments 
were created to address this concern, resulting in influential support for a restoration initiative in the Atlantic Forest. The Forest Code was further strengthened by a series of complementary laws, which increased the width of Areas of Permanent Protection and the percentage of Legal Reserves in the Amazon. In 1998, the Environmental Crimes Law (Law \# 9605/1998) established penal, civil and administrative penalties for individuals and companies responsible for environmental crimes, such as lack of compliance with the Forest Code, and thus designated forest restoration initiatives as a legal obligation for farmers and private companies [19]. From the 2000s onwards, the active role of Public Prosecution relative to environmental laws and the seeking of environmental certification by agricultural companies fostered large-scale restoration programs in many regions of the Atlantic Forest [18]. This trend of continuous strengthening of environmental laws changed in 2012, with the revision of the Forest Code (Law \# 12651/2012 — now called Law of Native Vegetation Protection) [18]. However, in spite of some environmental setbacks, six million hectares still should be restored or offset by tradable environmental certificates or protected area purchase in the coming years in the Atlantic Forest region in order to comply with the statements of this version of the Code [20].

In addition to the environmental laws mentioned above, which are related to ecological restoration, innovative legal instruments have arisen in recent years to regulate the practice of forest restoration and to increase its socio-ecological benefit, particularly regarding legal compliance, and by providing public funding for restoration [21]. In spite of societal awareness of the need for forest restoration, particularly in the Atlantic Forest, and the large number of legal instruments demanding it, restoration was disorganized, with poor dialogue among the multiple stakeholders and limited incentives for implementation prior to the launch of the AFRP.

\section{The Atlantic Forest Restoration Pact: Origin, Motivation and Major Goals}

Small-scale forest restoration initiatives have bloomed in the Atlantic Forest region since the 2000s as a result of the growing involvement of (1) environmental NGOs, which moved beyond a perspective of focusing solely on biodiversity conservation to include ecological restoration in their scope of activity; (2) farmers, forced by the Forest Code to restore portions of their lands; and (3) private companies, required to restore native ecosystems by biodiversity offsetting policies and, in some cases, to obtain environmental certification and market benefits [22]. For a variety of reasons, however, the incorporation of these three main groups of stakeholders into restoration activities did not result in a significant expansion of native forests. In the case of NGOs, their main approach to promote forest restoration was to convince farmers to allow restoration of their lands by offering to partially or totally cover the restoration costs in exchange for carbon credits or other benefits. This approach was needed because NGOs usually did not own lands on which to implement restoration projects and most degraded lands in Brazil are found on farmlands. However, most farmers were not interested in forest restoration because they could lose money through the conversion of agricultural land into native ecosystems and/or by investing time and money in the restoration process.

The government also failed to enforce the code related to farmland restoration, further eroding motivation for farmers to participate in restoration efforts, even though such efforts were, theoretically at least, required by law. Consequently, in spite of the existence of the Forest Code, the feeling of impunity caused by very low compliance levels reduced any pressure towards restoration of degraded 
private lands. This prevented the widespread involvement of farmers in restoration programs, and thus restoration projects led by NGOs or driven by the enforcement of the Forest Code quite often resulted in only very small patches of forests undergoing restoration and with poor integration at the landscape level [23]. Similar challenges arose at the private industry level regarding requirements for compensation and mitigation. Failures and loopholes in public policy, legal enforcement, and monitoring allowed companies to fulfill their legal commitments via the simple establishment of poorly designed tree plantations. Often abandoned after a few years, these plantations did not develop into biologically viable forest stands that could compensate society for the loss of native ecosystems elsewhere [24]. Even environmentally-committed companies interested in implementing effective restoration programs to comply with environmental laws, faced challenges to expanding their programs because of (a) technological constraints, (b) high costs of implementation and maintenance, (c) lack of economic incentives, (d) low ecological effectiveness and (e) weaknesses in the decision-making process [25].

The limitations described above demonstrated that large-scale forest restoration would not be achieved on a case-by-case approach, i.e., by individuals and independent farmers and companies obliged to restore their lands without enough incentives and a pro-active governance approach. This is reinforced by the fact that the decision-making process needed to promote changes in land use and allow restoration is intricately bound up within social, economic, juridical, political, historical and cultural factors [21]. This process cannot therefore be changed on a case-by-case approach or by a group of environmental NGOs. The probability of success is likely to increase however if restoration agents join forces to improve public policies, provide financial incentives for forest restoration while simultaneously discouraging degrading activities, develop appropriate legal instruments to foster and regulate restoration programs, and establish a good governance environment for forest restoration initiatives.

As a result, even though large numbers of conservation NGOs invested a lot of energy and funding to increase the scale of restoration in the biome in order to improve biodiversity conservation and provision of ecosystem services, the results were very disappointing and did not reverse the historical trend of habitat loss and degradation in the biome. Thus the degradation scenario remained the same at a landscape level, with many small and disconnected native forest patches embedded in a matrix dominated by agriculture, with no significant changes that would maintain biodiversity in such human-dominated landscapes [4]. A combination of the need to overcome the constraints preventing the scaling-up of restoration efforts in the Atlantic Forest, and to make certain "structural" transformations to expand forest restoration, stimulated a small group of NGOs and researchers to come together in 2006 to create a diverse coalition to foster large-scale forest restoration in the biome. The group knew that, to be effective, this coalition had to include a confluence of interests and agendas from all key forest restoration actors.

The group developed a plan to move forward and prioritized three steps leading up to the official launching of the AFRP in 2009: (1) engaging and inviting entities from diverse restoration stakeholder groups to join the coalition early in the process, in order to illustrate diversity and improve credibility and impact; (2) developing materials and distributing to members, e.g., a reference book with the lessons learned from 150 years of Atlantic Forest restoration history, restoration methodologies and techniques, a guide for practitioners to implement successful restoration projects, a map of potential restoration areas in the Atlantic Forest, and a website with an online registry system for the main restoration initiatives; and (3) establishing a target for the amount of hectares to be restored. These three steps were critical and 
challenging, but helped justify the need for such a coalition. Moreover, it was important to demonstrate that a coalition built to achieve large-scale restoration would not conflict with food production, but instead would provide many benefits for farmers and for society in general.

The process of realizing this goal was led by a group of researchers and NGOs. Based on current forest cover and on the target to achieve $30 \%$ of forest cover to comply with the Forest Code by 2050 , a total of 15 million hectares was established as the restoration target (Figure 1 and Table 1). However, as a result of the new Forest Code in 2012, there was a significant reduction in terms of restoration in the Atlantic Forest biome from about 8.7 to 6.2 million ha [20]. Therefore, to reach the 15 million ha goal the AFRP will need to develop economic restoration models to restore low-productive pasturelands (slope $>15^{\circ}$ ) that has low opportunity cost (less than US\$ 50/ha/year) due to the low productivity and return to the farmers. Another good reason to focus most of the restoration target on low-productivity pasturelands it to avoid competition with food, fuel and fiber production and supply to society.

Figure 1. Fifteen million ha of potential areas for forest restoration mapped in the Atlantic Forest by the Atlantic Forest Restoration Pact in Brazil.

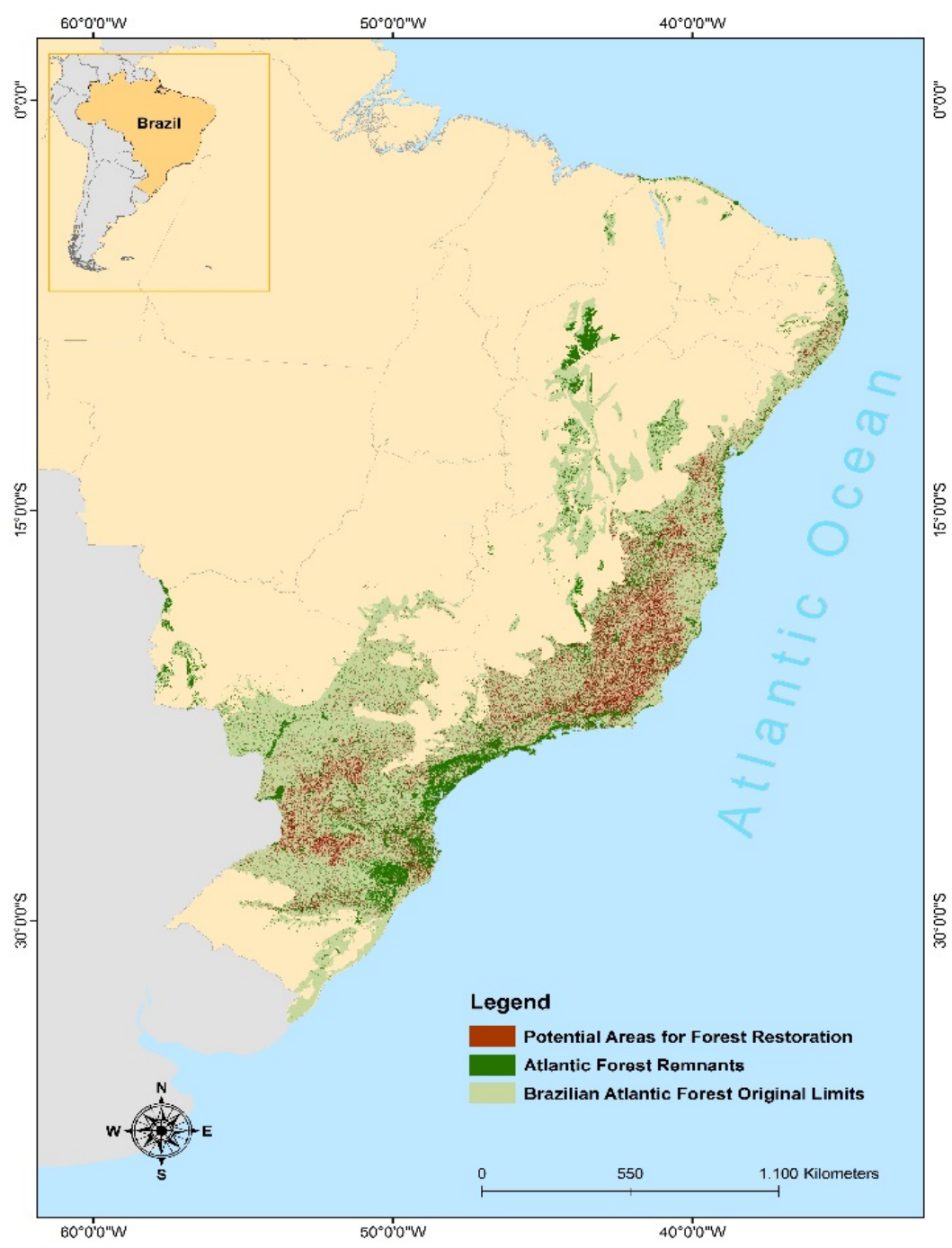


Table 1. Distribution of the original and remaining native vegetation cover in the Atlantic Forest biome, and potential areas for forest restoration mapped by the Atlantic Forest Restoration Pact.

\begin{tabular}{|c|c|c|c|c|c|}
\hline $\begin{array}{c}\text { Brazilian } \\
\text { region }\end{array}$ & State & $\begin{array}{l}\text { Original area (ha) of } \\
\text { Atlantic Forest in } \\
\text { each state }\end{array}$ & $\begin{array}{c}\text { Remaining area (ha) of } \\
\text { Atlantic Forest in each } \\
\text { state (2006) }\end{array}$ & $\begin{array}{l}\text { Potential areas } \\
\text { (ha) for } \\
\text { restoration in each } \\
\text { state (2009) }\end{array}$ & $\begin{array}{l}\text { Number of } \\
\text { members * }\end{array}$ \\
\hline \multirow[t]{3}{*}{ South } & Paraná & $19,480,507$ & $4,589,766$ & $2,455,536$ & 22 \\
\hline & $\begin{array}{l}\text { Rio Grande } \\
\text { do Sul }\end{array}$ & $13,545,367$ & $3,341,227$ & 891 & 16 \\
\hline & SantaCatarina & $9,421,487$ & $3,518,111$ & $1,402,182$ & 8 \\
\hline \multirow[t]{2}{*}{$\begin{array}{c}\text { Central- } \\
\text { West }\end{array}$} & $\begin{array}{l}\text { Mato Grosso } \\
\text { do Sul }\end{array}$ & $6,287,546$ & $1,123,919$ & 186.453 & 2 \\
\hline & Goiás & $1,050,484$ & not mapped & not mapped & 2 \\
\hline \multirow[t]{4}{*}{ Southeast } & $\begin{array}{l}\text { Espírito } \\
\text { Santo }\end{array}$ & $4,635,982$ & $1,010,845$ & $1,043,374$ & 22 \\
\hline & Minas Gerais & $27,660,939$ & $5,646,368$ & $5,648,980$ & 30 \\
\hline & $\begin{array}{l}\text { Rio de } \\
\text { Janeiro }\end{array}$ & $4,268,142$ & $1,341,634$ & 939.800 & 70 \\
\hline & São Paulo & $16,886,457$ & $3,898,490$ & $2,077,884$ & 131 \\
\hline \multirow[t]{8}{*}{ Northeast } & Alagoas & $1,508,873$ & 123.879 & 307 & 3 \\
\hline & Bahia & $18,955,797$ & $3,475,706$ & $2,104,511$ & 33 \\
\hline & Paraíba & 639 & 139 & 45 & 6 \\
\hline & Pernambuco & $1,804,087$ & 144.411 & 395 & 17 \\
\hline & $\begin{array}{l}\text { Rio Grande } \\
\text { do Norte }\end{array}$ & 314 & 103 & 40 & 2 \\
\hline & Sergipe & $1,103,048$ & 145 & 187.82 & 6 \\
\hline & Ceará & 885.423 & not mapped & not mapped & 0 \\
\hline & Piauí & $2,685,862$ & not mapped & not mapped & 0 \\
\hline Total & & $131,133,862$ & $28,603,105$ & $17,728,187$ & 370 \\
\hline
\end{tabular}

* Including volunteers, NGOs, private companies, state/local governments and research institutions.

After initial steps were executed and products generated, the AFRP was officially launched in April 2009, with the goal of restoring 15 million ha of the Brazilian Atlantic Forest by 2050 through the promotion of biodiversity conservation, jobs and income generation, ecosystem services maintenance and provisioning, and by supporting farmers to comply with the Forest Code across the 17 Brazilian states within this biome. To achieve this ambitious goal, the AFRP outlined the following objectives: (a) to establish biologically viable and diverse forests, (b) to enhance the capacity of human-modified landscapes to provide ecosystem services and biodiversity conservation, (c) to develop and implement land use plans that contemplate environmental legislation and minimize negative impacts from economic activities, (d) to build the business case for restoration, and (e) to generate socioeconomic benefits for society. 


\section{Key Governance Structures and Instruments Adopted by the Atlantic Forest Restoration Pact}

The AFRP has adopted seven governance structures and instruments, which connect and direct actions and stakeholders towards large-scale forest restoration.

\subsection{Members and Coordination Council}

The goal of achieving 15 million hectares of restoration and creating biodiversity-friendly and sustainable landscapes, imposes immense legal, technological, ecological, economic, and social challenges and actions. These actions need to be articulated, integrated, coordinated, shared, and aligned between the diverse members of the coalition. The process of becoming a member of the Pact is very simple: An individual or institution representative signs a declaration agreeing with the principles defined in the Protocol of the AFRP. After the institution or individual signs the declaration, the process is assessed by the Executive Secretariat and receives a password to formalize their registration online. Moreover, the process of becoming a member of the AFRP is voluntary and free of charges. The new member is also required to select a level of participation from the following categories: research and dissemination, project executor, public policy formulator, sponsor, seed and seedlings producer, or volunteer. This simple membership process ensures members are aligned with the general objectives and management standards of the AFRP — including the use of restoration technologies and the monitoring protocol - and promotes the exchange of any lessons learned, expertise, and experiences between members. Based on June 2014 figures, the AFRP has 267 members, distributed into four main categories of stakeholders: NGOs, private companies, governments, and research institutions (Figure 2). The majority of members, however, are still NGOs, thus challenging the AFRP to develop a more balanced representation from all categories, in particular the private sector and policy makers.

In order to attract new stakeholders and to mainstream members' involvement in the coalition, a Coordination Council and an Executive Secretariat operate as the central managing body of the AFRP. The Coordination Council is comprised of 21 member institutions (13 NGOs, three research institutions, three governmental agencies and two private companies) and is renewed every two years via an election process decided amongst the members. The roles and responsibilities of the Coordination Council are to establish a strategic plan and a vision for the coalition, and define short and medium-term goals, standards, rules, principles, and policies for the AFRP. The AFRP Coordination Council has a general coordinator and four vice-coordinator chairs representing each stakeholder category.

The role of the Executive Secretariat is to support and oversee the actions of the Council, provide technical and logistical support for capacity building and training courses/workshops for members, and oversee the preparation of primers and technical publications developed by the Pact members. The Secretary is also responsible for updating the website and the database of restoration projects being implemented by the members, engaging new members, and promoting information and experience sharing between members. Aside from the Executive Secretary, all other positions are voluntary and their time is paid by the institutions and organizations they represent as in-kind contributions, making AFRP a low-cost program that promotes the active engagement and participation of its members. 


\subsection{Regional Units}

One of the main challenges faced during the first two years of the AFRP was to unite stakeholders within the 17 states of the Atlantic Forest to get collectively behind the restoration and biodiversity goals. But there is an unbalanced distribution of members within the different geographical regions, which can raise some challenges considering the diversity of ecosystems within the overall 15 million a biome. For example, the Southeast region, in particular the state of São Paulo, has the highest concentration of members, but the majority of potential restoration areas are located in other Brazilian states and regions (Table 1). Thus, it was important to foster and engage the participation of stakeholders from other states and regions to legitimize the AFRP as a national movement. To resolve this, AFRP established "decentralized regional units", which are organized by groups of stakeholders from a given region, and which have the autonomy to establish their own Coordination Board, strategies, and work plans. The first regional unit was created in 2012 in the Alto São Francisco region, northeast of Brazil, and coordinated by a member NGO called Centro de Pesquisas Ambientais do Nordeste. AFRP is working to stimulate the creation of new regional units in all regions with poor representation and to increase the participation and engagement of a more diverse pool of stakeholders, establishing the AFRP as a truly collective movement within Brazilian society.

Figure 2. Number of members of each affiliation category of the Atlantic Forest Restoration Pact in 2011 and 2014; the percentage values included on the top of the bars represent the increase in the number of members in the period.

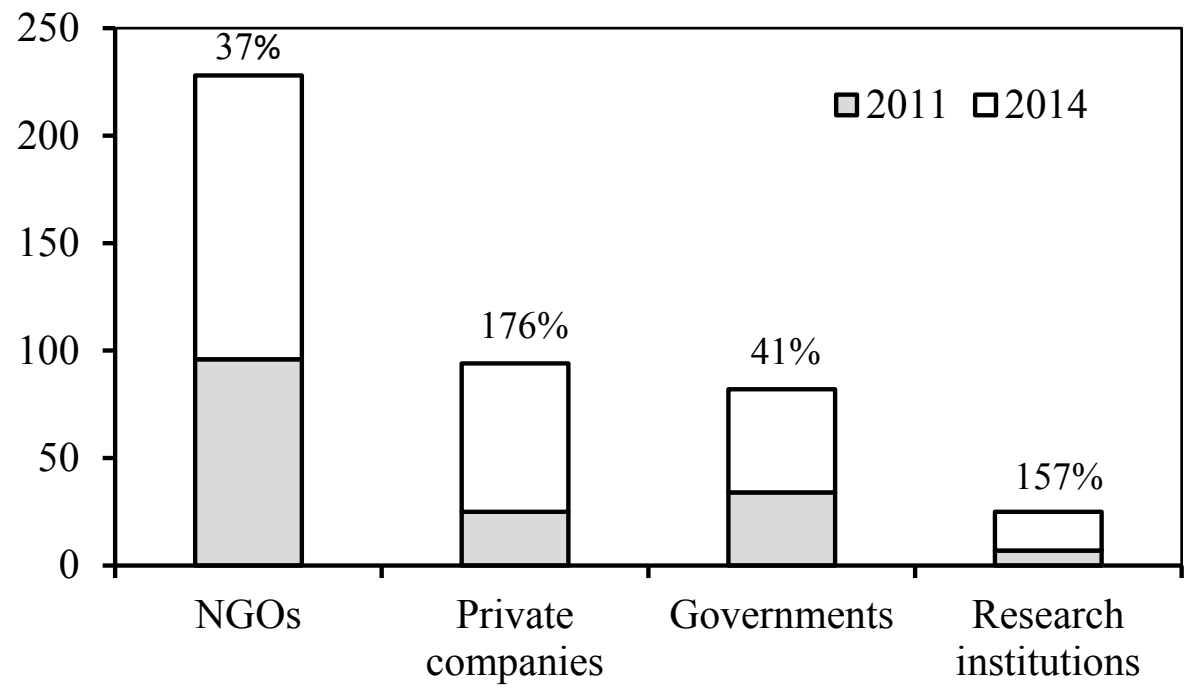

\subsection{Working Groups}

Because the AFRP could not rely on its own staff to accomplish its goal and objectives, it was necessary to take advantage of the constellation of experts and professionals within the different member institutions. Moreover, the cooperation and participation of different institutions throughout the decision-making process was essential for aligning and integrating members towards a common goal. With this in mind, the AFRP created six working groups (WGs) to coordinate and lead key themes, 
strategies, and activities. The main functions of the WGs were to (1) provide technical advice to the Coordination Council and the Executive Secretariat in their decision-making process, and (2) find solutions to overcome key barriers for up-scaling restoration initiatives. The six WGs are: Technical-Scientific, Socio-Economic, Fundraising, Public Policies, Information and Knowledge, and Communications and Marketing.

The Technical-Scientific WG is responsible for developing technologies and protocols for ecological restoration, and for building capacity of practitioners and implementers towards large-scale restoration. The Socio-Economic WG aims to transform ecological restoration into an economically viable activity by strengthening different components of the supply chain; evaluating costs, benefits, revenues, and risks associated with forest restoration; and developing innovative financial mechanisms for implementing restoration [15,23]. Two additional goals of this WG are to develop various business cases to attract entrepreneurs interested in investing in restoration, and to conduct research into the social benefits of forest restoration such job creation and income opportunities for farmers and communities. The Fundraising WG is responsible for organizing and approaching potential sponsors, donors, and investors to provide funding support for forest restoration projects, and for the maintenance of the AFRP main structure. The Public Policy WG creates and promotes the adoption of public policies, including legal and economic tools that can contribute to the quality and quantity of forest conservation and restoration in initiatives in the Atlantic Forest. This WG is also responsible for identifying and overturning perverse policies that hamper the advance of restoration in both ecological and socioeconomic terms [21]. In this context, it stimulates the restoration debate within both the AFRP and Brazilian civil society, proposes new regulatory frameworks and public policies, and lobbies for government to approve programs and projects that support ecological restoration. The Information and Knowledge WG is responsible for identifying gaps, organizing information and lessons learned from the projects' performance, mapping priority areas for forest restoration, and ultimately, developing knowledge products and tools that support restoration on the ground. For example, this WG is responsible for geo-referencing relevant information for restoration planning at a landscape level, such as the identification of eligible and suitable areas that supply water to major urban areas and/or for carbon sequestration. Finally, the Communication and Marketing WG is responsible for developing and implementing strategies and actions that disseminate the achievements of the Pact, promote internal and external communication among its members, and increase public awareness of the benefits that come from protecting and restoring the Brazilian Atlantic Forest.

\subsection{Training and Capacity Building}

Despite over 30 years of scientific background and experience in restoring the Atlantic Forest, the dissemination of this knowledge has occurred only in the last 5-10 years. As a consequence, ecological restoration can be considered a new activity for most of the practitioners, entrepreneurs, policy makers, and other professionals currently engaged in the AFRP. Training and capacity building programs, therefore, are crucial for increasing the scale and quality of restoration projects, and for engaging multiple stakeholders into a common conceptual framework. The AFRP has been building capacity by offering training courses on several topics to empower and increase knowledge among key actors, and to maintain partner engagement and alignment with the goals and objectives of the AFRP. 
One of the main achievements of the capacity building program has been the establishment and strengthening of partnerships with both national and international stakeholders. At the national level, many NGOs, private companies, and universities launched training programs in ecological restoration to address the demand for science-based knowledge on all parts of the forest restoration supply chain. Before the AFRP, each stakeholder had to learn by trial-and-error how to establish a nursery facility or to monitor the performance of the project, for example. Currently, several members of the AFRP are promoting training and courses within their area of influence and expertise. At the international level, some of the AFRP members have participated in training and capacity programs in Latin America. They have also disseminated the proven methodologies adopted by the AFRP members at different scales and for different sectors within the restoration supply chain.

\subsection{Monitoring Protocol}

The credibility of any major forest restoration program is dependent upon the quality of its projects, which can only be demonstrated via a well-designed, cost-effective, and transparent monitoring system with practical indicators. Several large-scale forest "restoration" initiatives have been publicly criticized because they did not meet certain international standards and criteria for ecological restoration. In China, for example, the planting of monoculture plantations with exotic commercial tree species in non-forested habitats was publicized as "forest restoration" [26]. Thus, the challenge of the AFRP is not only to foster the use of methods, techniques, and processes that will increase the likelihood of achieving high-diversity, biologically viable tropical forests, but also to monitor and report if those approaches have succeeded and if the areas being restored achieved the desired biological trajectory. The forest restoration projects included in the AFRP are being monitored through a participatory monitoring protocol that was developed by more than 50 partner institutions over almost three years. The "Monitoring Protocol of the AFRP, which is available online at the AFRP website, includes a set of criteria, indicators, and verifiers for monitoring the ecological, economic, social, and management factors considered critical for the success of any long-term forest restoration project. The main goal of a standard monitoring protocol for assessing the success of restoration projects is to allow comparison among methods, projects and socioeconomic approaches adopted by AFRP members. The results of this monitoring will transform the coalition into a large-scale experiment and provide key findings that will inform the continuous evolution of forest restoration practice and science in the Atlantic Forest.

A new web-based register and monitoring system is being developed to allow members of the AFRP to register their projects and assess their performance against the monitoring protocol indicators, and subsequently make the needed adjustments to ensure the likelihood of project success. Moreover, this system will also allow progress towards the restoration goal of the AFRP and the exchange of any useful lessons learned and other relevant experiences among the members and projects.

\section{Main Achievements and Challenges of the Atlantic Forest Restoration Pact}

The main challenge of the AFRP as a coalition during the first five years was to engage a critical mass and diversity of stakeholders involved with forest restoration initiatives and to create a favorable governance structure that could achieve the 15 -million ha restoration goal by 2050 . The engagement and involvement of more than 260 members from different stakeholder groups over the first five years of the 
AFRP was remarkable, and is rightfully considered a primary achievement. Although the AFRP has been successful in attracting members from various sectors, the representation of each of the four major sectors is not balanced due to an overrepresentation of environmental NGOs. Even though the NGOs make up the majority of the coalition, the other three categories grew significantly between 2011 and 2014, moving AFRP toward a greater balance in the near future. Another limitation of the AFRP has been the uneven geographical distribution of its members, with an overrepresentation of institutions from São Paulo state in the southeast region. Because more than $80 \%$ of potential areas for restoration are located outside the state of São Paulo (Table 1), it is urgent and desirable to have a targeted campaign that attracts members from other states and regions. We expect that the recent and pending creation of decentralized regional units will foster greater participation of underrepresented regions in the coalition.

It has become clear therefore that the success of the AFRP or any other similar coalition depends on the engagement and commitment of its members towards a common vision, goals, and objectives. It also depends on how well-represented the coalition is by all key groups of stakeholders, from the interest, geographic, and representation (e.g., government/business/NGO) perspective. Even though only two private companies are currently represented in the Coordination Council, they represent two of the most demanding sectors for forest restoration: the mining and pulpwood industries. One of these companies is Vale, the biggest mining company in Brazil, an actor highly committed to the vision and goals of AFRP. The second company is Fibria, which is the largest Brazilian pulp producer and which has committed itself to restoring more than 20,000 hectares throughout the next few years. The AFRP recognizes however that the over- or under-representation of sectors and geographical biases reduces the influence and impact of the coalition on national policies and may impose an additional challenge for governing a biome-wide restoration initiative. One solution currently underway is to increase and strengthen regional units, whereby leading members can engage and bring new and more diverse members to the AFRP.

It is also important to strengthen the connection between the AFRP and the agribusiness sector by promoting restoration beyond the conservation agenda, for example, by creating opportunities for investments by landowners and companies. Another important strategy is to create incentives to increase the level of compliance with the new Forest Code and therefore prevent additional changes and/or setbacks to this law.

Almost half of the AFRP's 15-million ha goal was based on the current deficit of Legal Reserves and Areas of Permanent Preservation. Because though the new Forest Code reduces requirements for Forest Restoration, members of AFRP are pursuing strategies and public policies to create new markets and financial incentives to promote "voluntary" restoration projects to meet the 15 million ha goal. These include creating new timber and non-timber forest products markets, promoting payments for ecosystem services (PES), marketing "certified" or environmentally friendly products, and developing more cost-effective approaches to forest restoration. Thus, forest restoration projects must provide a "basket of benefits" for landowners and for the different stakeholders that includes legal, social, environmental, and economic opportunities [23]. The AFRP has begun an initiative to benefit 30 small farmers in the Biodiversity Corridor of Northeastern Brazil, called the "Association of Native Seedlings Producers". The ultimate goal is to convert those farmers into restoration entrepreneurs [23]. The AFRP has also actively participated in the definition of the São Paulo state plan for the implementation of native forests 
designed for economic exploitation, as part of a bigger plan to create incentives to farmers and increase compliance with the Forest Code.

Policy makers are another stakeholder category that needs better representation in the AFRP, though their engagement has increased as they learned more about how the restoration supply chain can generate green jobs and income to rural communities. A group of AFRP members is actively engaged in discussing these and other public policies with politicians and policy makers. To provide a few examples, AFRP members: (1) laid out the technical and scientific background for protecting and restoring native ecosystems, while also counterbalancing the pressure of the agribusiness lobby when the new Forest Code was being debated; (2) influenced the governor of Pernambuco state to sign an agreement with the coalition to use the AFRP guidelines in forest restoration projects in the state and to offset the degradation caused by the construction of the Suape port, the biggest infrastructure project in Pernambuco state; and (3) achieved a collaboration of the Socio-Economic and Technical-Scientific WGs worked with the National Socio-Economical Development Bank (BNDES) to create financial programs capable of funding restoration projects in the Atlantic Forest.

The AFRP experience in the policy arena has shown that any large-scale forest restoration program cannot rely or depend upon legal compliance as the central motivating factor to achieve restoration targets, given that laws can change depending on the political scenario. Another important lesson is that forest restoration supporters must take an active part in political debates in order to inform and mobilize the public against potential legal setbacks in environmental policy. This requires active lobbying in favor of forest conservation and restoration and good scientific evidence to support these positions. The active involvement of society in political debates concerning forest conservation and restoration is particularly necessary in developing tropical countries, where the pressure to increase food production by replacing natural ecosystems with crops and pasturelands is still very high. In this context, one key part of the discussion about land sparing policies and strategies is that sustainable increases of productivity in cattle ranching could free up land to agriculture. This landscape approach requires coordination, integration, and synergy among agriculture, forest restoration, soil and biodiversity conservation policies, especially to avoid rebound effects where financial gains generated by the productivity improvements could be invested to convert more natural habitats into farm lands.

The production and the widespread use of the AFRP reference book is another major achievement of this coalition. Since most of the technical and scientific information on forest restoration in the Atlantic Forest was spread out among a variety of sources (e.g., scientific articles, books, primers, and proceedings), the organization, synthesis and editing of all relevant information into a reference publication by the Technical-Scientific WG improved the knowledge and awareness of key stakeholders on the science and practice of forest restoration immeasurably. This "state of the art" publication was made available for all members and partners as part of the formal launch of the AFRP and included a set of "technological packages" and "guidelines" on soil preparation, seed and seedling collection and production, planting methods, and management of restoration projects. More than 5000 print copies have been distributed since the launching of the AFRP in 2009, with many more distributed digitally through the AFRP's website [27]. Moreover, several of these protocols and guides have already been adapted and/or are in the process of being adapted to regional ecological and socioeconomic conditions [28]. One of the priorities of the AFRP is to update and translate this reference book into both English and Spanish. 
The performance of each WG varies depending on the capacity of the group members. The Technical-Scientific WG, for example, had a rather crucial role at the beginning of the AFRP in creating the main framework and products. This WG also developed tools to ensure the credibility and transparency of restoration efforts being undertaken by the AFRP members, such as guidelines and protocols to help monitor all restoration projects. The Information and Knowledge WG also played a critical role early on by developing the methodology for the potential forest restoration areas map. Some groups, however, have been more limited in their contribution to the AFRP to date. Even though the Fundraising WG have not yet been able to secure a sustainable funding source to maintain the main structure of the coalition and its members, they have made several attempts to mobilize funding and strategic partnerships to support the AFRP. They have been playing a very important role in inserting the AFRP into several global initiatives and have already established some valuable cooperation with the private sector and internationally-financed restoration projects. On the other hand, the Communication and Public Policy WGs are still in search of ways to add value to the coalition and its members. The most recent WG, the Socio-Economic, has been developing and making the business case for forest restoration. Within the next two years, the Socio-Economic WG expects to develop and/or promote innovative economic models to its members that will transform the way restoration is perceived by different sectors and by the public.

The AFRP should strengthen its efforts to make forest restoration a potential economic activity for landowners over the next few years. This medium-term goal is a pre-requisite for scaling-up forest restoration and thus restoring 15-million hectares of forests within the Atlantic forest biome. There is no question that this goal poses some challenges in terms of governance and technology, which will require a significant change in the way the members of the AFRP will be using and deploying their intellectual and human capital in the future.

\section{Conclusions}

The AFRP is a multi-institutional, multi-partner, bottom-up initiative, which aggregates ideas and actions to achieve large-scale restoration in the Atlantic Forest. By aligning interests and synergies, this cooperation has given a voice to different societal sectors interested in the multiple benefits of forest restoration, allowing the emergence and implementation of a biome-scale restoration initiative. Since its launch in 2009, the AFRP has become a stronger movement despite the economic crises the world has been facing. The governance mechanisms described above are considered fundamental towards achieving this end. Forest restoration for (1) biodiversity persistence, (2) provision of ecosystem services, and (3) socioeconomic development of rural areas would emphasize to multiple sectors of society the wide-ranging benefits of investing in native ecosystems. Not only has the AFRP been expanding its efforts and impacts on the ground, it has also tried to inspire other countries and restoration initiatives to follow a similar approach towards achieving large-scale restoration. The governance mechanisms described above are fundamental for the success of this type of coalition. The AFRP still needs to overcome several challenges, but our experience has shown that a multi-stakeholder network is the clearest way towards realizing large-scale restoration and generating the full range of social, economic, and environmental benefits for the entire society. By sharing the ARFP experience we hope to offer inspiration, lessons and guidance in terms of a general approach, while also acknowledging the 
multiple challenges that may arise. It is recognized that most tropical biodiversity hotspots lack such a diversity of actors and institutional entities, but the experiences and expertise generated by the ARFP during the last five years can serve as inspiration, providing valuable lessons and models for any large-scale initiative.

\section{Acknowledgments}

We wish to thank Manuel Guariguata for the invitation to participate and contribute to this Special Issue. We would also like to thank Simon Dunster and Bethanie Walder for English revision and the members of Atlantic Forest Restoration Pact for the information provided and the inspiration to move forward. This article was published with funding support from Improving the way knowledge on forests is understood and used internationally (KNOW-FOR) program provided by International Union of Conservation of Nature (IUCN). The KNOW-FOR program is funded by the Department for International Development (DFID). The paper expresses views/opinion of authors and not of IUCN/DFID.

\section{Author Contributions}

Severino R. Pinto, Marcelo Tabarelli, Felipe Melo, Ricardo G. César and Pedro H.S. Brancalion leaded the preparation and review of the manuscript, while Aurélio Padovesi, Carlos A. Mesquita, Carlos A.M. Scaramuzza, Pedro Castro, Helena Carrascosa, Miguel Calmon and Ricardo Rodrigues actively participated in the development of the Atlantic Forest Restoration Pact and provided general information for the preparation of the manuscript and contributed with the review process.

\section{Conflicts of Interest}

The authors declare no conflict of interest.

\section{References and Notes}

1. Brancalion, P.H.S.; Melo, F.P.; Tabarelli, M.; Rodrigues, R.R. Biodiversity persistence in highly human modified tropical landscapes depends on ecological restoration. Trop. Conserv. Sci. 2013, 6, 705-710.

2. Mcconnachie, M.M.; Cowling, R.M.; Shackleton, C.M.; Knight, A.T. The challenges of alleviating poverty through ecological restoration: insights from South Africa's "Working for Water" Program. Restor. Ecol. 2013, 21, 544-550.

3. Aronson, J.; Alexander, S. Ecosystem restoration is now a global priority: Time to roll up our sleeves. Restor. Ecol. 2013, 21, 293-296.

4. Melo, F.P.L.; Arroyo-Rodríguez, V.; Fahrig, L.; Martínez-Ramos, M.; Tabarelli, M. On the hope for biodiversity-friendly tropical landscapes. Trends. Ecol. Evo. 2013, 28, 462-468.

5. Menz, M.H.M.; Dixon, K.W.; Hobbs, R.J. Hurdles and opportunities for landscape-scale restoration. Science 2013, 339, 526-527.

6. Mcqueen, C.; Noemdoe, S.; Jezile, N. The working for water programme. Land Use Water Resour. Res. 2001, 1, 1-4. 
7. Arriagada, R.A.; Ferraro, P.J.; Sills, E.O.; Pattanayak, S.K.; Cordero-Sancho, S. Do payments for environmental services affect forest cover? A farm-leve evaluation from Costa Rica. Land Econ. 2012, 88, 382-399.

8. Mittermeier, R.; Turner, W.; Larsen, F.; Broks, T.; Gascon, C. Global Biodiversity Conservation: The Critical Role of Hotspots; Springer Berlin Heidelberg: Berlin, German, 2011; pp. 3-22.

9. Brancalion, P.H.S.; Viani, R.A.G.; Calmon, M.; Carrascosa, H.; Rodrigues, R.R. How to organize a large-scale ecological restoration program? The framework developed by the Atlantic Forest restoration pact in Brazil. J. Sustain. For. 2013, 32, 728-744.

10. Rodrigues, R.R.; Lima, R.A.F.; Gandolfi, S.; Nave, A.G. On the restoration of high diversity forests: 30 years of experience in the Brazilian Atlantic Forest. Biol. Conserv. 2009, 142, $1242-1251$.

11. Dean, W. With Broadax and Firebrand: The Destruction of the Brazilian Atlantic Forest; University of California Press: London, UK, 1995; p. 485.

12. Victor, M.A.M.; Cavalli, A.C.; Guillaumon, J.R.; Filho, R.S. Cem Anos de Devastação; Brazilian Environmental Ministry: Brasília, Brazil, 2005; p. 72.

13. Laurance, W.F. Conserving the hottest of the hotspots. Biol. Conserv. 2009, 142, 1137.

14. Tabarelli, M.; Roda, S.A. Oportunidade para o Centro de Endemismo Pernambuco. Natur. Cons. 2005, 3, 22-28.

15. Brancalion, P.H.S.; Cardozo, I.V.; Camatta, A.; Aronson, J.; Rodrigues, R.R. Cultural ecosystem services and popular perceptions of the benefits of an ecological restoration project in the Brazilian Atlantic forest. Restor. Ecol. 2014, 22, 65-71.

16. Calmon, M.; Brancalion, P.H.S.; Paese, A.; Aronson, J.; Castro, P.; Silva, S.C.; Rodrigues, R.R. Emerging threats and opportunities for large-scale ecological restoration in the Atlantic Forest of Brazil. Restor. Ecol. 2011, 19, 154-158.

17. Sparovek, G.; Berndes, G.; Klug, I.L.F.; Barreto, A.G.O.P. Brazilian agriculture and environmental legislation: status and future challenges. Environ. Sci. Technol. 2010, 44, 6046-6053.

18. Garcia, L.C.; Santos, J.S.; Matsumoto, M.; Silva, T.S.F.; Padovezi, A.; Sparovek, G.; Hobbs, R.J. Restoration challenges and opportunities for increasing landscape connectivity under the New Brazilian Forest. Act. Natur. Cons. 2013, 11, 181-185.

19. Durigan, G.; Melo, A.C.G. Panorama das políticas públicas e pesquisas em restauração ecológica no estado de São Paulo. In Conservación de la Biodiversidad en las amÉricas: Lecciones y Recomendaciones de Política; Figueroa, E., Ed.; Universidad de Chile: Santiago, Chile, 2011; pp. 355-387.

20. Soares-Filho, B.; Rajão, R.; Macedo, M.; Carneiro, A.; Costa, W.; Coe, M.; Rodrigues, H.; Alencar, A. Cracking Brazil's Forest Code. Science 2014, 344, 363-364.

21. Aronson, J.; Brancalion, P.H.S.; Durigan, G.; Rodrigues, R.R.; Engel, V.L.; Tabarelli, M.; Torezan, J.M.D.; Gandolfi, S.; Melo, A.C.G.; Kageyama, P.Y.; et al. What role should government regulation play in ecological restoration? Ongoing debate in São Paulo State, Brazil. Restor. Ecol. 2011, 19, 690-695.

22. Wuethrich, B. Reconstructing Brazil's Atlantic Rainfores. Science 2007, 315, 1070-1072. 
23. Brancalion, P.H.S.; Viani, R.a.G.; Strassburg, B.B.N.; Rodrigues, R.R. Finding the money for tropical forest restoration. Unasylva 2012, 63, 41-50.

24. Maron, M.; Hobbs, R.J.; Moilanen, A.; Matthews, J.W.; Christie, K.; Gardner, T.A.; Keith, D.A.; Lindenmayer, D.B.; Mcalpine, C.A. Faustian bargains? Restoration realisities in the context of biodiversity offset policies. Biol. Conserv. 2012, 155, 141-148.

25. Tollefson, J. Brazil revisits forest code. Nature 2011, 476, 259-260.

26. $\mathrm{Xu}, \mathrm{J}$. China's new forests aren't as green as they seen. Nature 2011, 447, 371.

27. Rodrigues, R.R.; Brancalion, P.H.S.; Isernhagen, I. Pacto Pela Restauração da Mata Atlântica: Referencial dos Conceitos e Ações de Restauração Florestal; Instituto BioAtlântica: São Paulo, Brazil, 2009.

28. Rodrigues, R.R.; Gandolfi, S.; Nave, A.G.; Aronson, J.; Barreto, T.E.; Vidal, C.Y.; Brancalion, P.H. Large-scale ecological restoration of high-diversity tropical forests in SE Brazil. For. Ecol. Manag. 2011, 261, 1605-1613.

(C) 2014 by the authors; licensee MDPI, Basel, Switzerland. This article is an open access article distributed under the terms and conditions of the Creative Commons Attribution license (http://creativecommons.org/licenses/by/3.0/). 